\title{
Loneliness and the Contributing Factors in the Elderly Patients with Type II Diabetes: A Descriptive Cross-sectional Study
}

\author{
Parvin Yousefzadeh ${ }^{1}$, Farideh Bastani ${ }^{2}$, Hamid Haghani ${ }^{3}$, Razieh Sadat Hosseini ${ }^{4}$
}

\begin{abstract}
Background \& Aims: Diabetes is a chronic, lifelong disease that could occur at any age. The incidence of type II diabetes increases with age. According to the International Diabetes Federation (IDF), the prevalence of type II diabetes is higher among the elderly compared to other age groups. Type II diabetes is associated with various complications and may lead to several physical and mental problems in the elderly. Loneliness is one of the psychological complications in the elderly with chronic diseases such as diabetes. Loneliness is a unique psychological structure, which is characterized by feeling unhappy due to the lack or reduction of the expected interpersonal relationships. Loneliness is an important indicator of psychological health, with a twoway relationship with diabetes as it is also an important factor in the treatment of these patients. Loneliness in the elderly could lead to chronic diseases such as cardiac disorders, hypertension, stroke, obesity, diabetes, lung diseases, and even death. Identifying the psychological issues associated with diabetes is prioritized in health care. The present study aimed to assess loneliness and the contributing factors in the elderly with type II diabetes in order to determine the significant factors that may be associated with loneliness. Examining the state of loneliness as a psychological component in the elderly with diabetes could lay the groundwork for nursing interventions and improving healthcare resources for these patients.

Materials \& Methods: This descriptive, cross-sectional study was conducted on 257 elderlies diagnosed with insulin-dependent type II diabetes referring to the comprehensive health centers of the elderly affiliated to Iran University of Medical Sciences during October-December, 2019. The participants were selected via continuous sampling. The inclusion criteria were consent to participate, age of 60 years or more, no cognitive impairment (minimum score of 7 out of 10 in cognitive impairment test), ability to communicate, no known mental illnesses (based on the medical records statement of the patient), and definitive diagnosis of insulindependent diabetes (based on medical record). Data were collected using a demographic questionnaire consisting of data on age, gender, marital status, occupation status, education level, insurance status, type of insurance, housing state, having a companion/support in life, the most important needs in life, and living with others. In addition, we used the abbreviated mental test (AMT), which is a short cognitive test for the cognitive assessment of the elderly. AMT consists of 10 items, with scores $\leq 7$ indicating the presence of a cognitive disorder (maximum score: 10). Another tool was the University of California at Los Angeles (UCLA) questionnaire, which was developed by Russell et al. in 1980 and has 20 four-response items, 10 negative statements, and 10 positive statements. This scale is used to measure the degree of loneliness. In the present study, the revised version of the loneliness questionnaire was used, and the content validity was confirmed by two faculty members. In addition, the reliability was confirmed at the Cronbach's alpha of 0.9. Data analysis was performed in SPSS version 16 using descriptive statistics, including absolute frequency distribution and frequency percentage for qualitative variables and mean and standard deviation for quantitative variables, to
\end{abstract}

\footnotetext{
'. Master of Geriatric Nursing, School of Nursing and Midwifery, Iran University of Medical Sciences, Tehran, Iran r. Department of Nursing, Community Health, and Ageing, School of Nursing and Midwifery, Iran University of Medical Sciences, Tehran, Iran (Corresponding author) Tel: +98-02143651820 Email: bastani.f@iums.ac.ir r. Department of Biostatistics, School of Health, Iran University of Medical Sciences, Tehran, Iran

${ }^{\uparrow}$. Nursing Care Research Center, Department of Community Health Nursing, School of Nursing and Midwifery, Iran University of Medical Sciences, Tehran, Iran
} 
describe the characteristics of the samples. Independent t-test and analysis of variance (ANOVA) were also applied for statistical analysis.

Results: In total, $55.3 \%$ of the elderlies were aged 60-69 years. The sample population included $55.3 \%$ women and $44.7 \%$ men. Approximately $65.4 \%$ the participants lived with their spouse, and $96.9 \%$ had insurance. Regarding the correlation between loneliness and demographic characteristics in the patients, it was observed that age $(\mathrm{P}<0.001)$, marital status $(\mathrm{P}<0.001)$, occupation status $(\mathrm{P}<0.001)$, living with another elderly $(\mathrm{P}<0.001)$, maximum support $(\mathrm{P}<0.001)$, the most important needs in life $(\mathrm{P}<0.001)$ and insurance status $(\mathrm{P}=0.032)$ were significantly correlated with loneliness. In addition, paired comparison by Tukey's test indicated that the feeling of loneliness was more significant in the elderly aged more than 80 years compared to those aged 60-69 years. Loneliness was significantly less in the married patients compared to the divorced, widowed, and single elderlies, while it was also significantly less in the widowed elderlies compared to the singles $(\mathrm{P}=0.003)$. Overall, $82.1 \%$ of the elderly patients reported slight loneliness, whereas $17.9 \%$ reported significant feelings of loneliness.

Conclusion: According to the results, feelings of loneliness were associated with the demographic and clinical characteristics of the elderly with insulin-dependent type II diabetes. Unlike most studies, the score of loneliness was relatively low in the current research, and the discrepancy may be due to the presence of trained elderly nurses in the ward and the demographic and clinical characteristics of the participants. Given the growing number of the elderly patients with type II diabetes, proper strategies should be adopted to improve physiological and psychological health of these individuals. Patients with type II diabetes (especially insulindependent diabetes) are more likely to feel lonely, and increased loneliness may reduce their desire and motivation for treatment. Therefore, we believe that nurses, physicians, and other healthcare providers should pay attention to the effects of loneliness on these patients during treatment and clinical care. In addition, preventive measures should be taken, and the importance of the issue should be explained to patients and their caregivers. It is recommended that interventional studies be performed to reduce the feeling of loneliness in the elderly with chronic diseases (e.g., diabetes). Furthermore, opportunities should be provided for the public awareness of the importance of loneliness as a mental health alert that may affect chronic illnesses (e.g., diabetes) and even mortality.

Keywords: Elderly, Loneliness, Insulin-dependent Type II Diabetes, University of California at Los Angeles (UCLA) Questionnaire

\section{Conflict of Interest: No}

How to Cite: Yousefzadeh P, Bastani F, Haghani H, Hosseini RS. Loneliness and the Contributing Factors in the Elderly Patients with Type II Diabetes: A Descriptive Cross-sectional Study. Iran Journal of Nursing. 2021; 33(128):27-39.

Received: 7 Nov 2020

Accepted: 6 Feb 2021 


\section{احساس تنهايى و عوامل مرتبط با آن در سالمندان مبتلا به ديابت نوع دو: يك مطالعه}

\section{توصيفى- مقطعى}

يروين يوسفز اده '، فريده باستانى '، حميد حقانى '، راضيه سادات حسينى

زمينه و هدف:. شناسايى مشكلات روانشناختى مر تبط با بيمارى ديابت به يكى از اولويتهاى مر اقبتهاى بهاشاشتى تبديل شده است. احساس

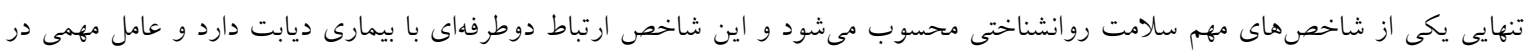

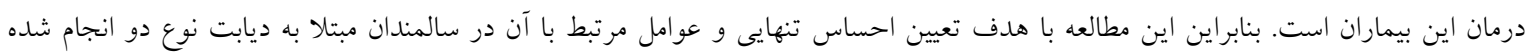

روش بررسى: يزوهش حاضر، يك مطالعه توصيفى- مقطعى است. در اين مطالعه rOV نفر از سالمندان مبتلا به ديابت نوع دو وابسته به به انسولين

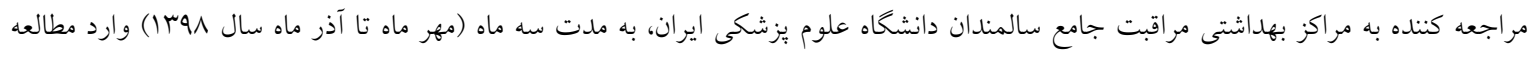

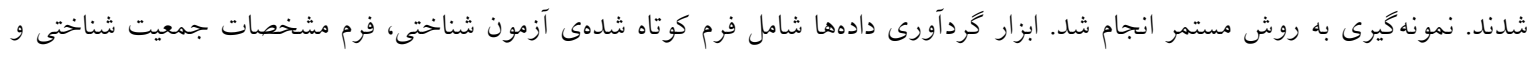

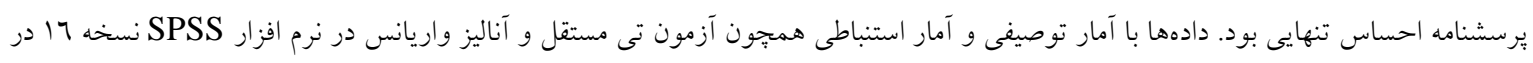

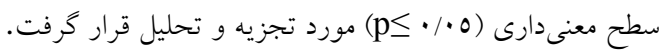

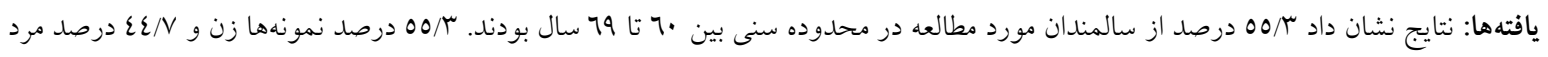

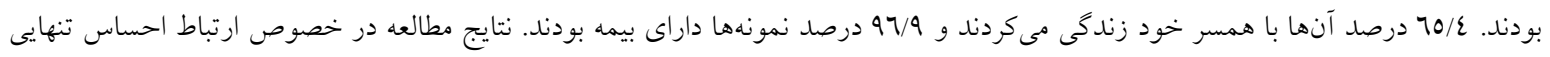

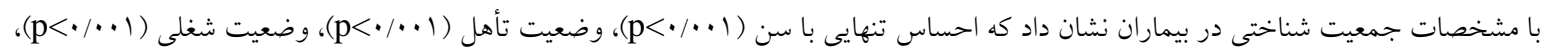

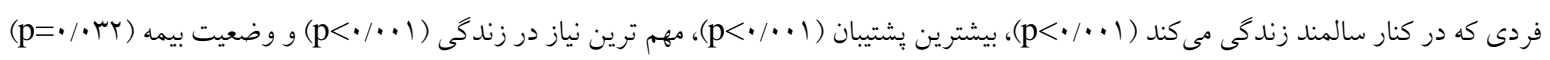

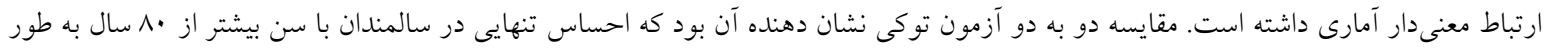

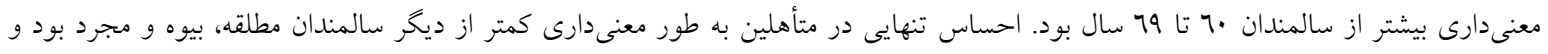

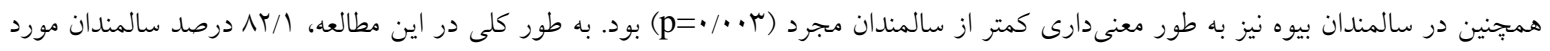

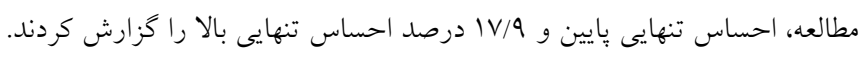

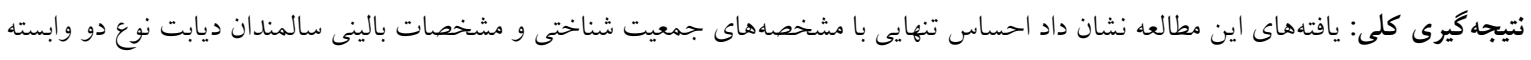

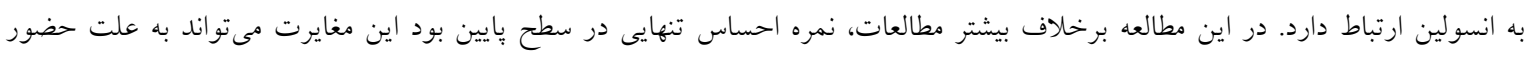

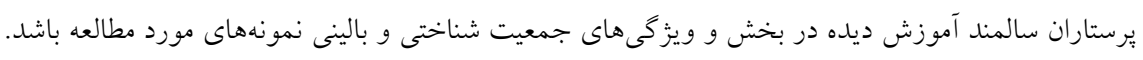

كليد وازهها: سالمند، احساس تنهايى، ديابت نوع دو وابسته به انسولين، برسشنامه احساس تنهايى UCLA تعارض منافع: ندارد تاريخ دريافت: 99/N/IV

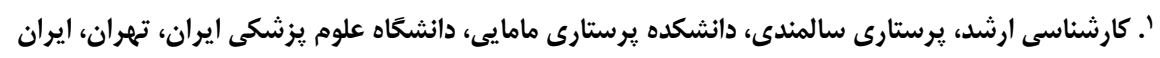

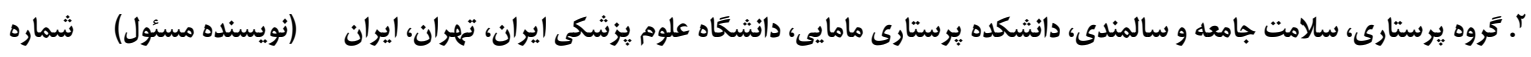

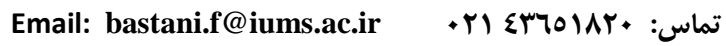

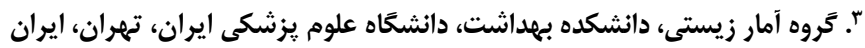

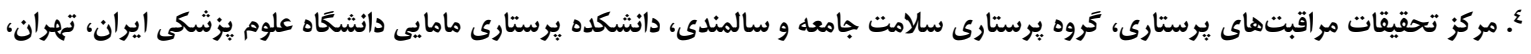


تاريخ بذيرش: 99/11/11

اين مطالعات نتايج نشان داده است ارتباطى دو طرفه بين مقدمه

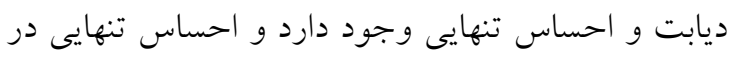

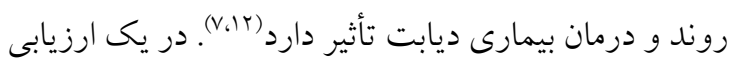
طولانى مدت نيز مشخص شد احساس تنهايى با ميزان

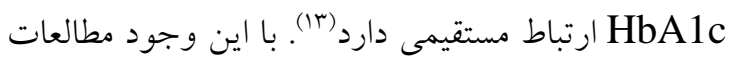

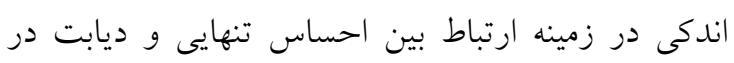
سالمندان وجود دارد و تاكنون مطالعهاى در ايران در اين زمينه انجام نشده است. با توجه به وضعيت آسيبيذير سالمندان مبتلا به ديابت آنسان

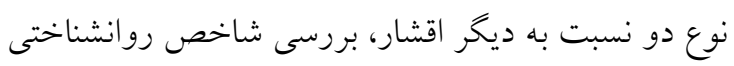

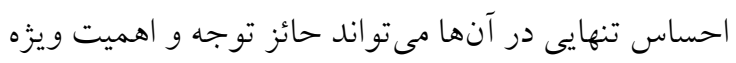

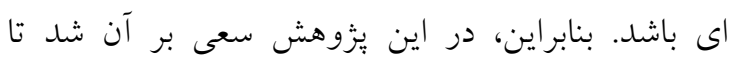
احساس تنهايى و عوامل مرتبط با آن در بين سالمندان مبتلا به ديابت نوع دو مورد بررسى قرار كيرد.

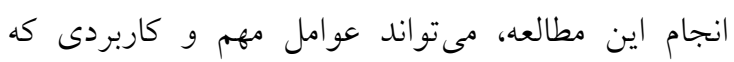

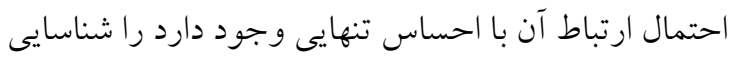
كند و هم جنين با بررسى وضعيت احساس تنهايى، بهعنوان

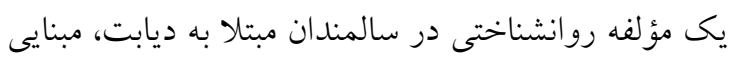

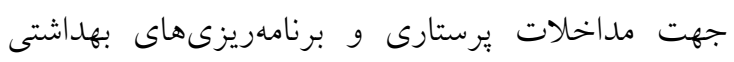

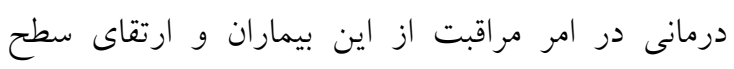
سلامتى آنان باشد.

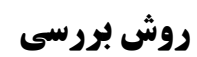

يزوهش حاضر يكى مطالعه توصيفى - مقطعى است. جامعه

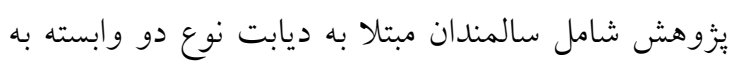
انسولين مراجعه كننده به مراكز مراقبت جامع سالمندان

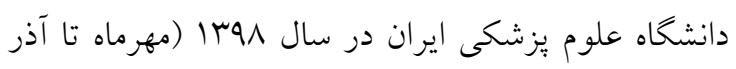

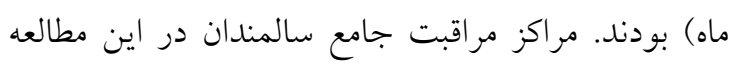

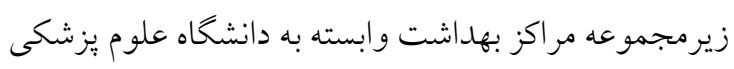

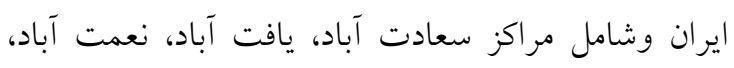

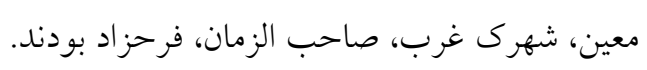

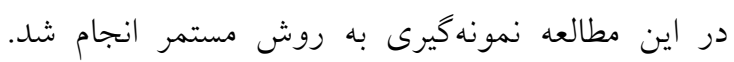

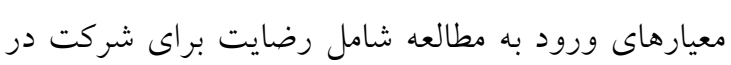

ديابت يك بيمارى مزمن و مادام العمر است كه ممكن است

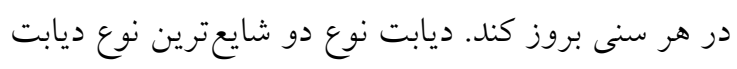

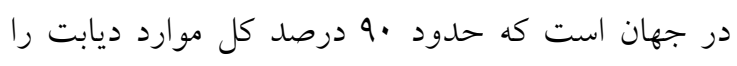

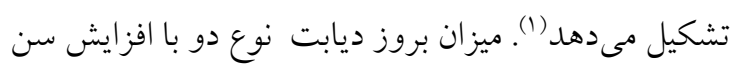

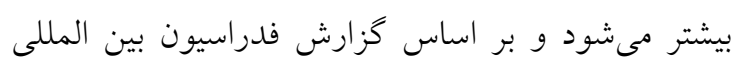
ديابت (IDF) شيوع ديابت نوع دو در بين سالمندان بيشتر

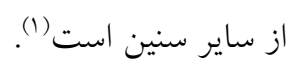
ديابت نوع دو با عوارض مختلفى همر اه است و مىتواند

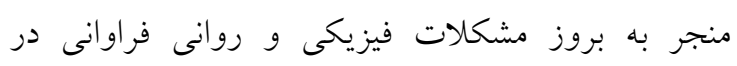

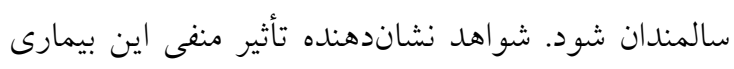

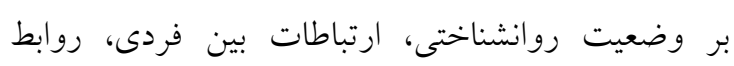
اجتماعى و خانو ادگى افراد است (r). اين بيمارى بر كاركرد

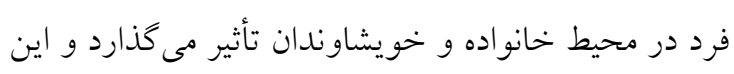

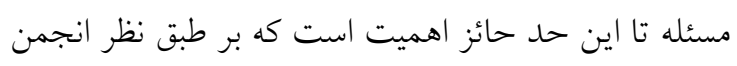
بين المللى ديابت، يكى از بزرگترين مشكلات اورين اورزانس جهانى است ("). از جمله مشكلات روانشناختى در سالمندان مبتلا به بيمارى

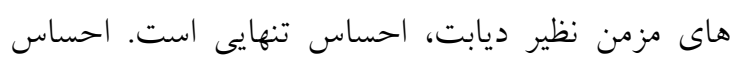

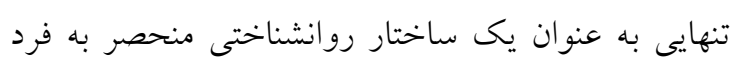

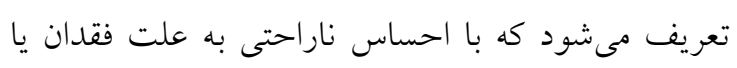

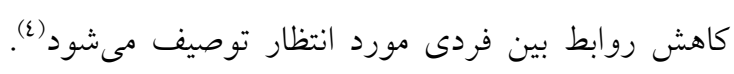

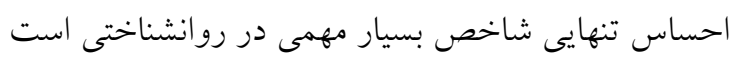

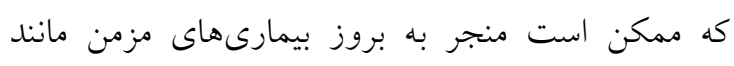

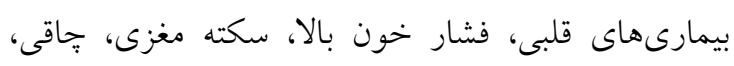

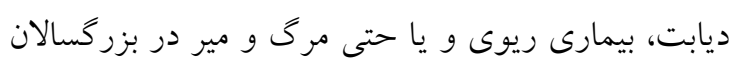
شود (0-^)

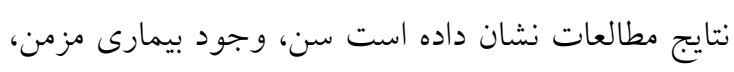
سطح تحصيلات، وضعيت اقتصادى و وضعيت تأهل از

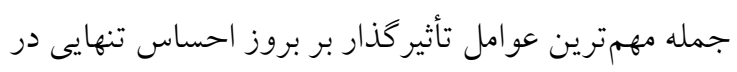
افر اد هستند (11-9). مطالعات مختلف جنبههاى مختلفى از احساس تنهايى با هـان

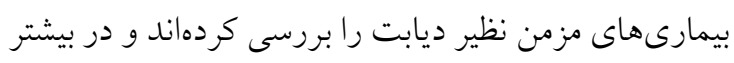


صورت طيف ليكرت جهار نقطهاى مىباشد كه براى كزينه

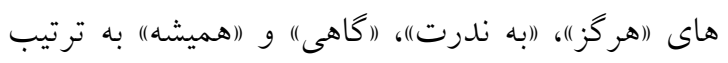

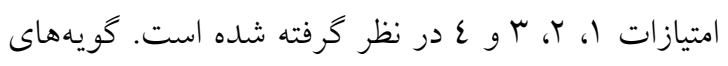

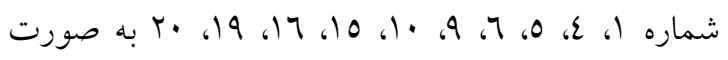
معكوس نمرهخذارى مىشوند. براى به دست آوردن امتياز

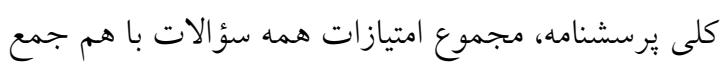

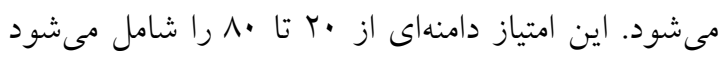

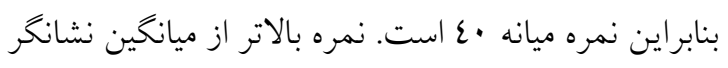

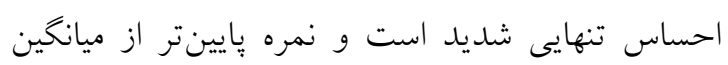
نشانكر احساس تنهايى خفيف مىباشد. روايى صورى و

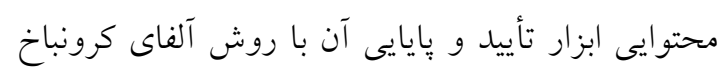

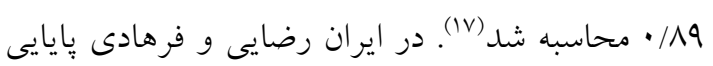

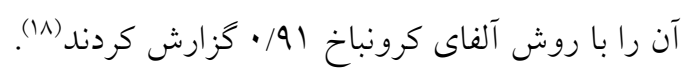

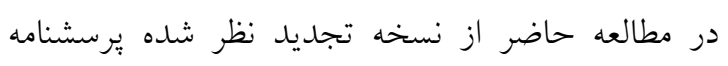

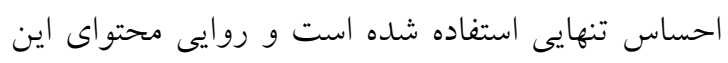
ابزار توسط دو نفر از اعضاى هيئت علمى تأييد كرديد و يايايى آن با روش آلفاى كرونباخ ه / • محاسبه شد. دادهها

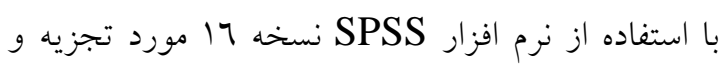
تحليل قرار گرفت. براى توصيف مشخصات نمونهها از آمار توصيفى شامل توزيع فراوانى مطلق و درصد فراوانى ترونى

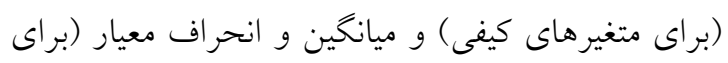

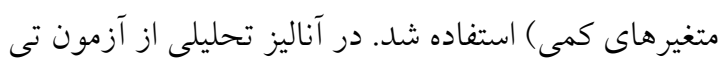

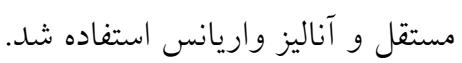

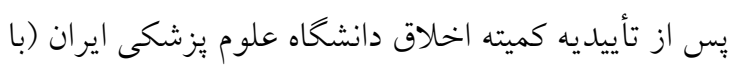
كد اخلاق

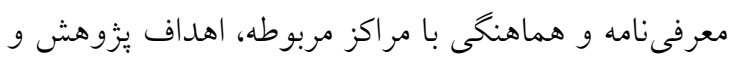

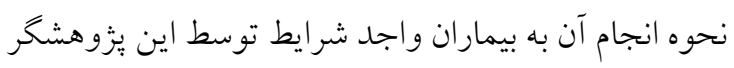

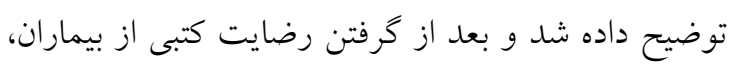

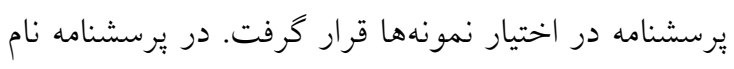

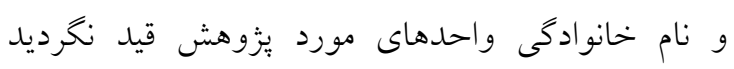

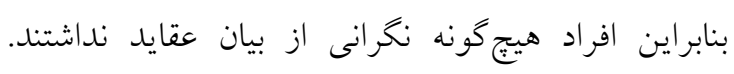

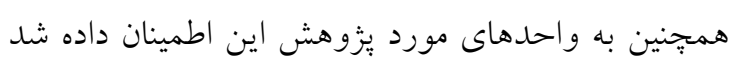

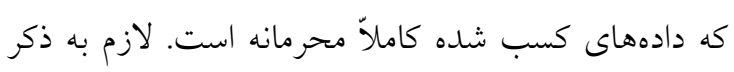

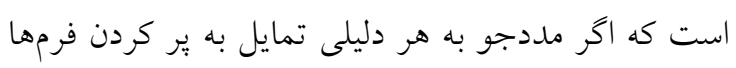

مطالعه، سن •7 سال به بالا، نداشتن اختلال شناختى (كسب

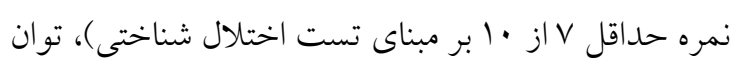
برقرارى ارتباط و وجود نداشتن بيمارى روانى شناخته شده

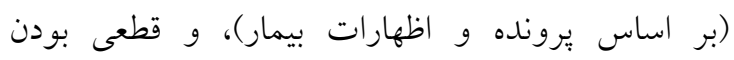
تشخيص ديابت وابسته به انسولين (بر اساس يرونده) بود.

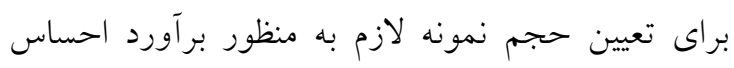

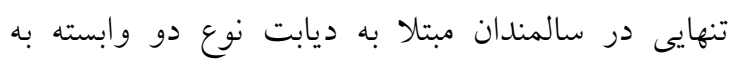

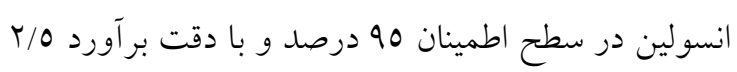
نمره ·اب نفر برآورد كرديد.

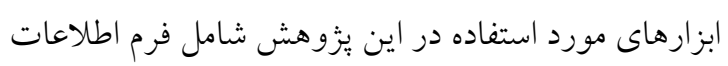
جمعيت شناختى بود كه مشخصههاى سن، جنسيت، وضعيت تأهل، شغل، تحصيلات، وضعيت بيمه، نوع بيمه،

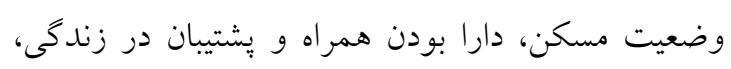

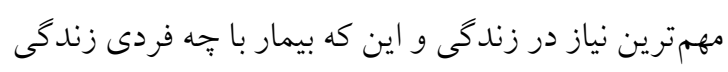

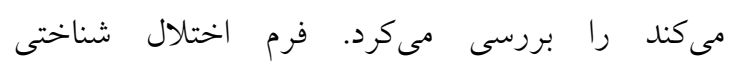
كه آزمون (Abbreviated Mental Test (AMT)) كوتاه شناختى بوده و جهت ارزيابى شناختى سالمندان جهت ورود به يزوهش استفاده شد. اين يرسشنامه شامل

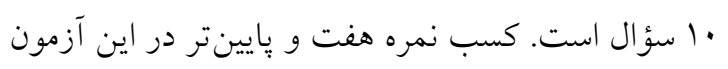

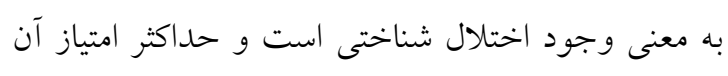

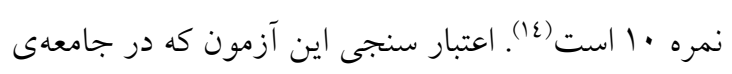

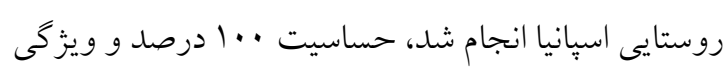

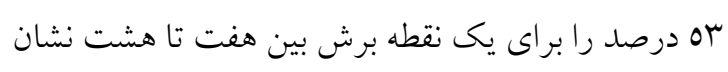

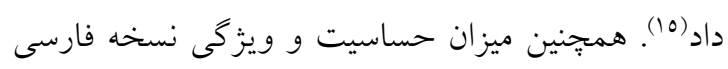
آزمون كوتاه شده شناختى بر اساس معيارهاى DSMIV

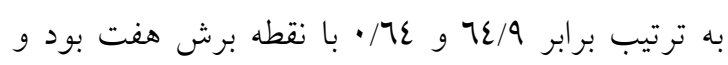

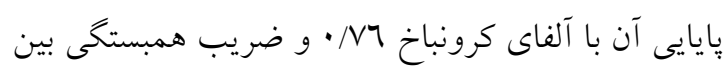

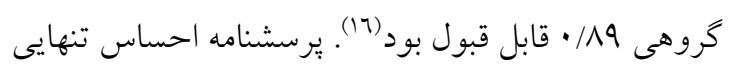
University of California at Los Angeles ) (questionnaire /UCLA

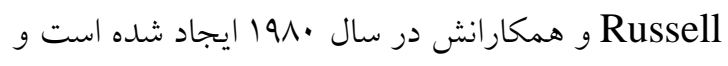

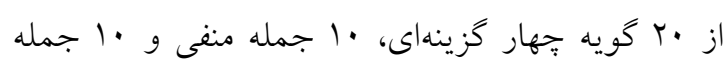

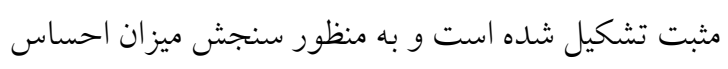

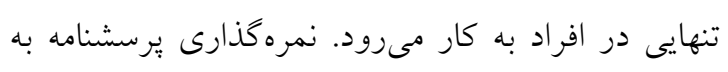


ميانخين نمره كسب شده در سالمندان بيكار به طور معنى

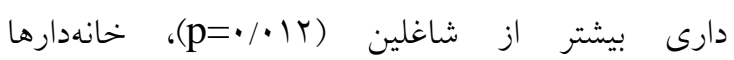

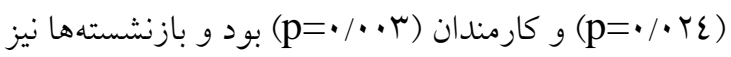

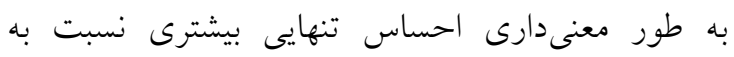

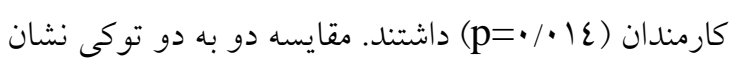

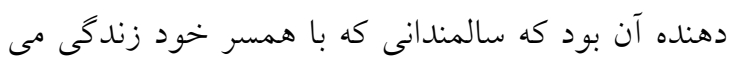

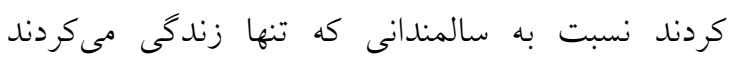

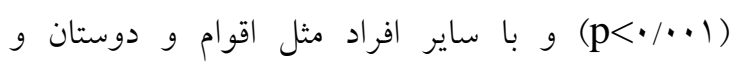

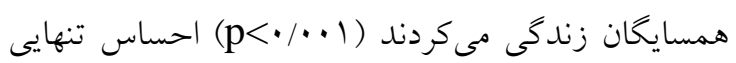

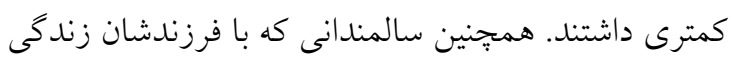

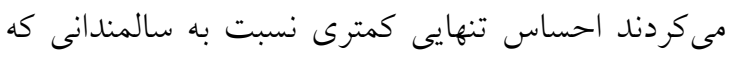

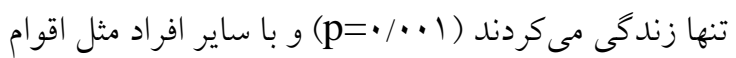

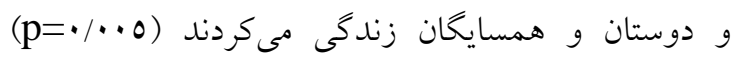
داشتند. سالمندانى كه همسر خود را به عنوان پِشتيبان اعلام

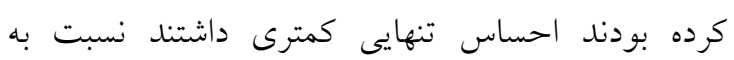

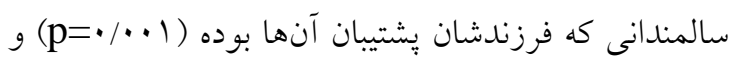

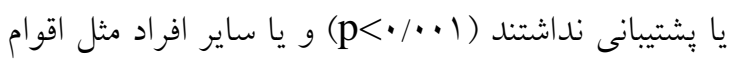

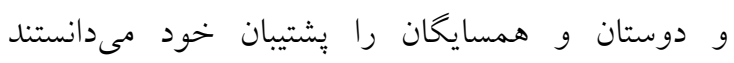

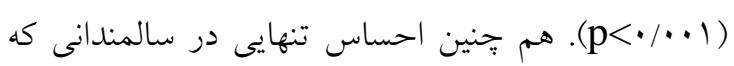

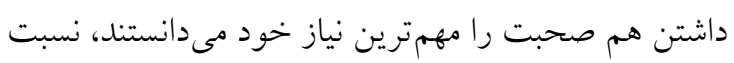

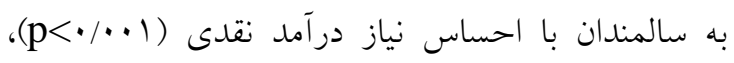

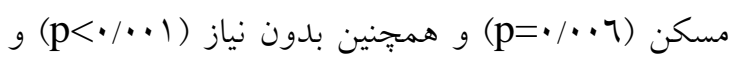

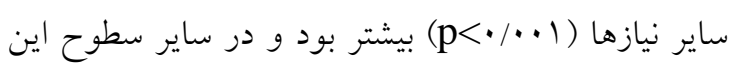

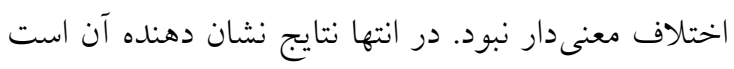

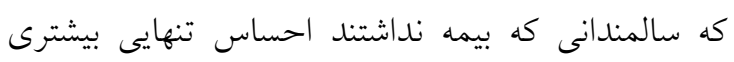

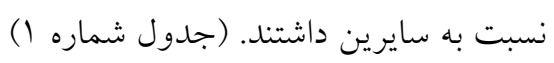

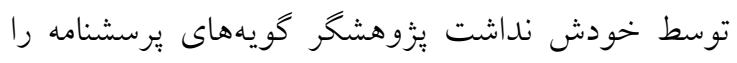

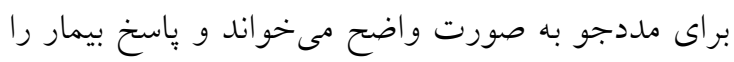

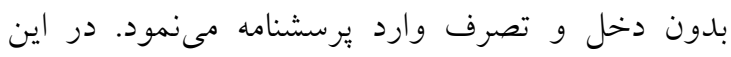

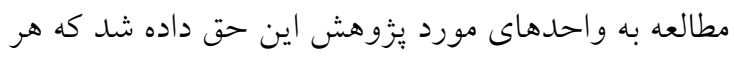

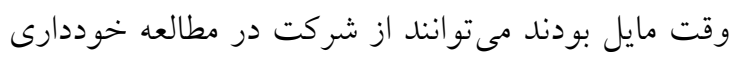
نمايند.

\section{يافتهها}

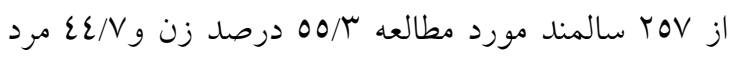

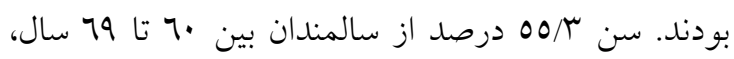

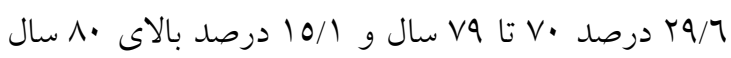
بودند. ساير مشخصات جمعيت شناختى و مشخصات بالينى نمونههاى مورد مطالعه در جدول شماره ا و ب آمده

بررسى ارتباط احساس تنهايى با مشخصات جمعيت

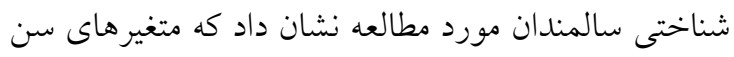

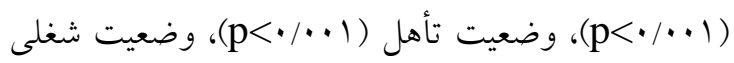

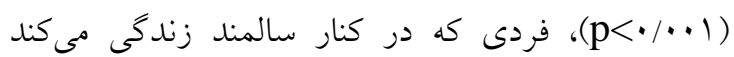

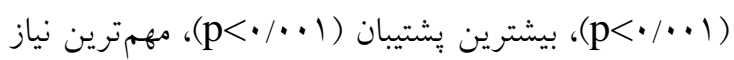

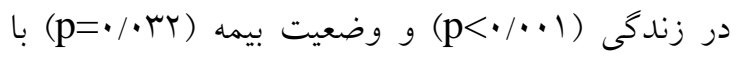
احساس تنهايى ارتباط معنىدار آمارى داشتند.

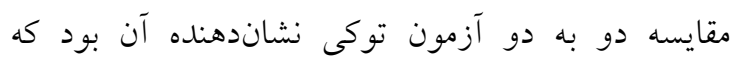

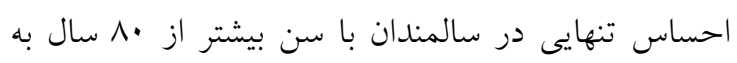

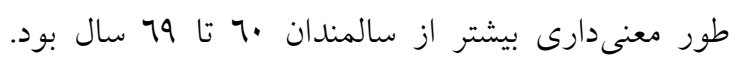
احساس تنهايى در متأهلين به طور معنى دارى كمتر از ديخر سالمندان مطلقه، بيوه و مجرد بود و همجينين در سالمندان

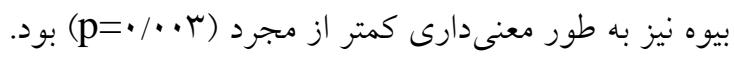


جدول شماره ا: توزيع فراوانى مشخصات جمعيت شناختى و ارتباط آن با احساس تنهايى در سالمندان مبتلا به ديابت نوع دو وابسته به انسولين

\begin{tabular}{|c|c|c|c|c|c|c|}
\hline \multirow{2}{*}{ نون آناليز واريانس } & \multirow{2}{*}{$\begin{array}{l}\text { P value } \\
F=\wedge / r 7 r\end{array}$} & \multirow{2}{*}{ انحر اف معيار } & \multirow{2}{*}{$\begin{array}{l}\text { ميانكين } \\
\text { ro/7 }\end{array}$} & \multirow{2}{*}{ فراوانى (درصد) } & \multicolumn{2}{|c|}{ مشخصات فردى } \\
\hline & & & & & $7 \cdot-79$ & سن (سال) \\
\hline & $\mathrm{P}<\cdot / \cdot \cdot 1$ & $\mid r / \cdot r$ & rANr & $(r q / 0) V 7$ & $v \cdot-v q$ & \\
\hline & & $\mid r / \varepsilon \varepsilon$ & $\varepsilon \Gamma / \Lambda \varepsilon$ & $(10 / r) r q$ & •^ و بالاتر & \\
\hline \multirow[t]{2}{*}{ تى مستقل } & $\mathrm{t}=1 / .0 \mathrm{r}$ & IT/AY & $r_{N / 70}$ & $(\varepsilon \varepsilon / V) \| 10$ & مرد & جنس \\
\hline & $\begin{array}{l}\mathrm{df}=r 00 \\
\mathrm{P}=\cdot / r 9 \varepsilon\end{array}$ & $1 . / 7 \varepsilon$ & $r V / M$ & $(00 / r) \backslash \varepsilon r$ & زن & \\
\hline \multirow{4}{*}{ آناليز واريانس } & $\mathrm{F}=\cdot / \mathrm{N97}$ & $1 r / r q$ & $r 9 / 70$ & $(r 7 / \Lambda) 79$ & بىسواد & \\
\hline & $\mathrm{P}=\cdot / \varepsilon q \vee$ & $1 \cdot / r r$ & $r V / r$ & $(r \cdot) v V$ & كمتر از دييلم & سطح تحصيلات \\
\hline & & $11 / .0$ & rq/ar & $(Y) / A) 07$ & دييلم & \\
\hline & & $\mid r / r r$ & $r v / r$ & $(Y Y / L) 00$ & دانشخاهى & \\
\hline \multirow[t]{4}{*}{ آناليز واريانس } & $\mathrm{F}=I V / \varepsilon V \varepsilon$ & $1 . / 19$ & revo & $(70 / 1) 179$ & متأهل & \\
\hline & & $I T / A V$ & $\varepsilon \varepsilon / 0 \varepsilon$ & $(N / \tau) r r$ & مطلقه & وضعيت تأهل \\
\hline & $\mathrm{P}<\cdot / \cdot .1$ & $11 / r$ & $\varepsilon 1 / 0 r$ & $(Y Y / Y) O V$ & بيوه & \\
\hline & & $1 \cdot / 11$ & $O \varepsilon / M$ & $(r / 0) 9$ & مجرد & \\
\hline \multirow[t]{5}{*}{ كروسكال واليس } & $\mathrm{P}<\cdot / \cdot \cdot 1$ & 1.119 & $r \varepsilon / 0$ & $(1 \cdot / 1) Y 7$ & آزاد & \\
\hline & & $1 . / \varepsilon r$ & rq/V7 & $(\Gamma N / q)) \ldots$ & خانهدار & وضعيت شغلى \\
\hline & & $|\xi| \cdot Y$ & $\varepsilon \cdot \mu_{0}$ & $(r V / N) q V$ & بازنشسته & \\
\hline & & $V / \Lambda$ & $r Y / 01$ & $(1 . / 0) T V$ & كارمند & \\
\hline & & $\mid 1 / \wedge 1$ & 0. & $(T / N) \vee$ & بيكار & \\
\hline \multirow[t]{4}{*}{ آناليز واريانس } & $\mathrm{F}=r \cdot / \wedge 0 \wedge$ & $1 \cdot \% \varepsilon$ & $r \varepsilon / \eta \Lambda$ & $(70 / r) 171$ & همسر & \\
\hline & $\mathrm{P}<\cdot / . \cdot 1$ & $1 . / 70$ & $r_{V / \varepsilon \Lambda}$ & $(I r / \Lambda) r r$ & فرزندان & با جه كسانى زندكى \\
\hline & & Ir/TO & $\sum 7 / 70$ & (19) $\varepsilon 9$ & تنها & مى كنيد؟ \\
\hline & & $\varepsilon / 7 V$ & Or/L & $(Y N) \vee$ & ساير & \\
\hline \multirow[t]{4}{*}{ كروسكال واليس } & $\mathrm{P}<\bullet / \cdot \cdot 1$ & $9 / r$ & $r \mu / 0$ & $(09 / 9) 10 \varepsilon$ & همسر & بشترين فرد يشتيبان \\
\hline & & $1 . / 9 \varepsilon$ & $r q / q$ & $(19 / 0) 0$. & فرزندان & در انجام امور \\
\hline & & $I r / T$ & $\{V / N)$ & $(17 V) \varepsilon r$ & هيجكس & روزمره \\
\hline & & $V / 71$ & $0 . / \varepsilon$ & $(r / q))$. & ساير & \\
\hline \multirow[t]{6}{*}{ آناليز واريانس } & $\mathrm{F}=1.1 / 190$ & $9 / \Lambda V$ & $r y / \varepsilon 7$ & $\left(r_{N / 0} 99\right.$ & درآمد نقدى & \\
\hline & $\mathrm{P}<\cdot / \cdot \cdot 1$ & $1 . / 9 r$ & rV/OV & $(0 / \varepsilon) \mid \varepsilon$ & مسكن & مهم ترين نياز در \\
\hline & & $11 / 0 r$ & $\varepsilon 9 / \wedge r$ & $(\mid T / M) M$ & هم صحبت & زندگى \\
\hline & & $I T / N r$ & $\sum r / 0$ & $(7 / r) 17$ & يذيرش در اجتماع & \\
\hline & & $11 / 07$ & $r\{N \mid$ & $(T V / T) V \cdot$ & بدون نياز & \\
\hline & & $N / A V$ & ro & $(q / r) \Gamma \varepsilon$ & ساير & \\
\hline \multirow[t]{2}{*}{ تى مستقل } & $\mathrm{P}=\cdot / \cdot r \mathrm{r}$ & $11 / 29$ & $r V / \varepsilon \Lambda$ & $(97 / \Lambda) Y \sum q$ & دارد & وضعيت بيمه \\
\hline & & $1 \% / 0 \mathrm{~V}$ & $\varepsilon V / T r$ & $(r / r) \wedge$ & ندارد & \\
\hline
\end{tabular}


سالمندانى كه سابقه بسترى در بيمارستان داشتند، مصرف دارو به جز انسولين نداشتند و سابقه خانوادگى ابتلا به ديابت نداشتند، احساس تنهايى بيشترى نسبت به سايرين تجربه كرده بودند (جدول شماره r).
ارتباط احساس تنهايى با مشخصات بالينى سالمندان مورد

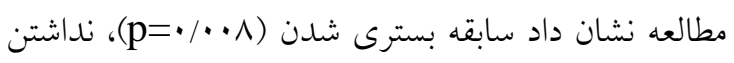

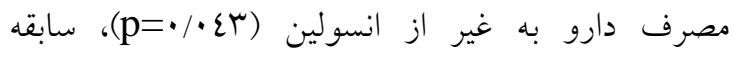
خانوادكى ابتلا به ديابت (7ع •/p=) با احساس تنهايى ارتباط معنىدار آمارى داشته است و مشخص گرديد

جدول شماره r: توزيع فراوانى مشخصات بالينى و ارتباط احساس تنهايى با آن در سالمندان مبتلا به ديابت نوع دو وابسته به انسولين

\begin{tabular}{|c|c|c|c|c|c|}
\hline نتايج آزمون تى مستقل & انحر اف معيار & & فراوانى (درصد) & & مشخصات بال \\
\hline $\mathrm{t}=\mathrm{r} / \mathrm{MAr} \quad \mathrm{df}=\mathrm{r} 00$ & $11 / M$ & rN/qE & $(V r / 9) 19$. & دارد & سابقه بسترى شدن \\
\hline $\mathrm{P}=\bullet / \cdots \wedge$ & $1 \cdot 120$ & $r \varepsilon / 00$ & $(r T / 1) T V$ & 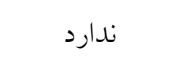 & \\
\hline$t=\cdot / v \vee q \quad d f=r 00$ & $11 / 17$ & ry/lv & $(1 \cdot / 9) \mathrm{rA}$ & كمتر از اسال & مدت ابتلا به ديابت \\
\hline $\mathrm{P}=\cdot / \varepsilon r V$ & $11 / 70$ & r & $(\wedge q / 1)$ rrq & بيشتر از | سال & \\
\hline$t=\cdot / \varepsilon r l \quad d f=r 00$ & $11 / \mathrm{V} 1$ & $r \Lambda / \cdot \Lambda$ & (OH/V) IrA & كمتر از 1 سال & مدت استفاده از انسولين \\
\hline $\mathrm{P}=\cdot / \tau \vee \varepsilon$ & $11 / 70$ & $r V / \varepsilon V$ & $(\varepsilon 7 / r) 119$ & بيشتر از 1 سال & \\
\hline$t=r / \cdot r 7 \quad d f=r 00$ & $1 \cdot 104$ & $r / 7$ & $(7 \cdot / r) 100$ & دارد & مصرف دارو به غير از انسولين \\
\hline $\mathrm{P}=\cdot / \cdot \varepsilon r$ & $1 \% / .0$ & $r q / 71$ & $(r q / V) 1 \cdot r$ & 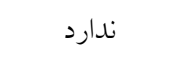 & \\
\hline$t=r / \cdots 9 \quad \mathrm{df}=r 00$ & $11 / 29$ & $m / / 9$ & $(V Y / \varepsilon) \backslash \wedge T$ & دارد & سابقه خانو ادگى ابتلا به ديابت \\
\hline $\mathrm{P}=\cdot / \cdot\{\rceil$ & $11 / A V$ & $\varepsilon \cdot / 10$ & $(Y V / T) V I$ & 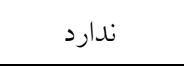 & \\
\hline$t=l / \wedge \varepsilon 0 \quad d f=r o 0$ & $11 / 11$ & $r q / 0 \varepsilon$ & $(r V) 90$ & دارد & يرفشارى خون \\
\hline $\mathrm{P}=\cdot / \cdot 77$ & $11 / 29$ & $\mathrm{rupv}$ & (Tr) & 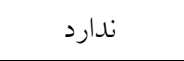 & \\
\hline$t=\cdot / \varepsilon q \varepsilon \quad \mathrm{df}=r 00$ & $11 / 1 \pi$ & rN/19 & $(20 / 1) 117$ & دارد & جربى خون \\
\hline $\mathrm{P}=\cdot / \pi T r$ & $\mid r / T$ & rV/ $/ \varepsilon V$ & $(0 \varepsilon / 9)|\varepsilon|$ & 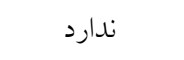 & \\
\hline $\mathrm{t}=\cdot / \cdot 77 \quad \mathrm{df}=r 00$ & $11 / 71$ & rV/Vo & $(0 . / 7) 1 \%$. & دارد & آرتروز \\
\hline $\mathrm{P}=\cdot / q \varepsilon V$ & $11 / \mathrm{VV}$ & rV/Ao & $(\varepsilon q / \varepsilon) \mid r V$ & 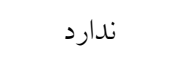 & \\
\hline$t=\cdot / l V r \quad d f=r 00$ & $1 \% / \cdot 1$ & $\mathrm{rV} / 07$ & $(Y Y / T) O \Lambda$ & دارد & تيروئيد \\
\hline $\mathrm{P}=\cdot / \wedge \pi \mu$ & $11 / 09$ & rV/AT & $(V V / \varepsilon) 199$ & 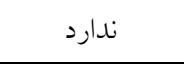 & \\
\hline$t=\cdot / 0 \cdot V \quad d f=r 00$ & $11 / A r$ & rN/vı & $(1 T / 0) r T$ & دارد & كليوى \\
\hline $\mathrm{P}=\cdot / 71 \mu$ & $11 / 77$ & $r V / 77$ & $(A V / O)$ YTO & 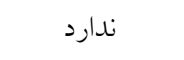 & \\
\hline $\mathrm{t}=\cdot / / \vee q \quad \mathrm{df}=r 00$ & $1 \cdot / 20$ & $r N / T V$ & $(\mathrm{~V}) \backslash \wedge$ & دارد & يوستى \\
\hline $\mathrm{P}=\cdot / \wedge \circ \wedge$ & $11 / \mathrm{VV}$ & $r V / v T$ & (qu) & 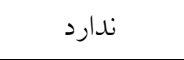 & \\
\hline $\mathrm{t}=\cdot / \varepsilon \wedge 1 \quad \mathrm{df}=r \Delta 0$ & $|r / T|$ & rN/OQ & $(17 / r) \varepsilon r$ & دارد & ساير \\
\hline $\mathrm{P}=\cdot / 7 \pi /$ & $11 / 07$ & $r V / T \varepsilon$ & $(\Lambda r / v) Y 10$ & 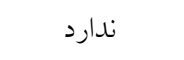 & \\
\hline
\end{tabular}


نتايج رگرسيون خطى نشان داد در بين مشخصات جمعيت شناختى نشان داد وضعيت شغلى (خانهدار) بيشترين تأثير را در احساس تنهايى داشته است (جدول شماره ع). همجنين نتايج رگرسيون خطى در بين مشخصات باتئ دالينى نشان داد سابقه بسترى با ضريب استاندارد ب 19/• بيشترين

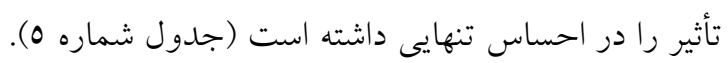

ميانخين و انحراف معيار احساس تنهايى در سالمندان مبتلا به ديابت نوع دو وابسته به انسولين در اين مطالعه II/TV

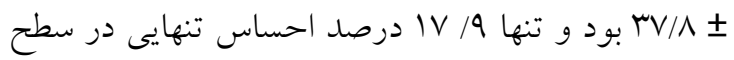
بالا داشتند. (جدول شماره r)

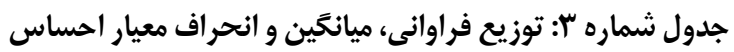

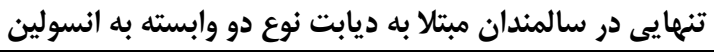

\begin{tabular}{|c|c|c|}
\hline درصد & فراوانى & احساس تنهايى \\
\hline$\Lambda Y / l$ & $\$ 11$ & پايين (كمتر از •0) \\
\hline $1 V / 9$ & $\varepsilon 7$ & زياد (.0 و بالاتر) \\
\hline $1 \cdots$ & rov & جمع كل \\
\hline \multicolumn{2}{|c|}{$\mathrm{rV} / \mathrm{A} \pm 11 / \mathrm{TV}$} & انحراف معيار 土 ميانخين \\
\hline \multicolumn{2}{|c|}{$r Y-V \varepsilon$} & بيشينه -كمينه \\
\hline
\end{tabular}

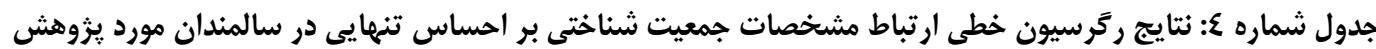

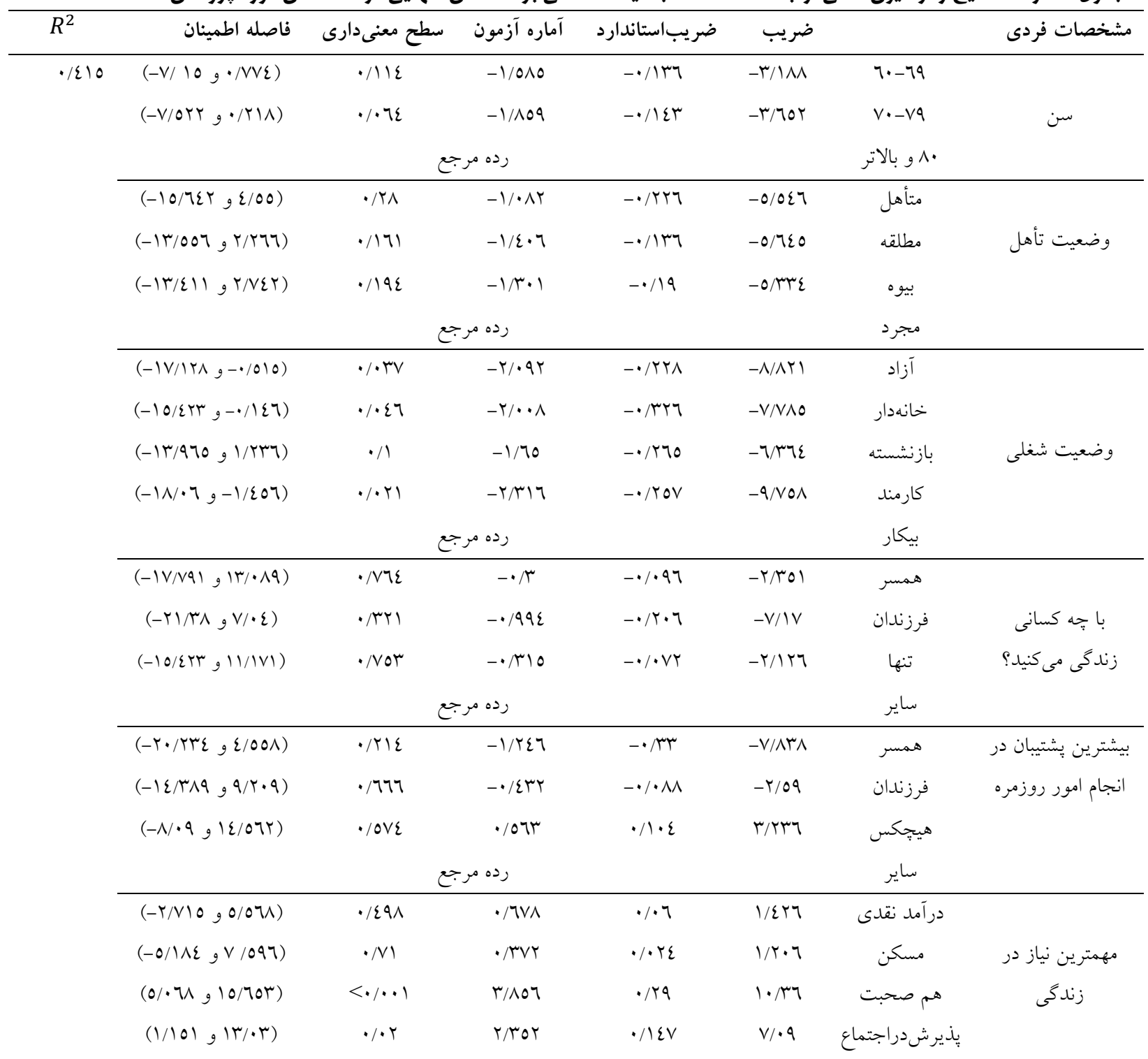




\begin{tabular}{|c|c|c|c|c|c|c|}
\hline$(-\varepsilon / 09 V, \varepsilon / / 0 V)$ & $\cdot / 9 T 1$ & $\begin{array}{l}-. / .99 \\
020\end{array}$ & $-\cdot / \cdot \cdot 1$ & $-\cdot / T r$ & بدون نياز & \\
\hline$(-1 \varepsilon / \Gamma \varepsilon \wedge, \cdot / N q \vee)$ & $\cdot / \cdot v q$ & $\begin{array}{l}-\mid / V 71 \\
\text { رده }\end{array}$ & $-\cdot / 1$ & $-7 / V Y T$ & ندارد & وضعيت بيمه \\
\hline
\end{tabular}

جدول شماره ه: نتايج ركر سيون خطى ارتباط مشخصات بالينى بر احساس تنهايى در سالمندان مورد يزوهش آنش

\begin{tabular}{|c|c|c|c|c|c|c|c|}
\hline R2 (ضريب تعيين) & فاصله اطمينان & سطح معنىدارى & آماره آزمون & ضريب استاندارد & ضريب & \multicolumn{2}{|c|}{ مشخصات بالينى } \\
\hline \multirow[t]{6}{*}{$\cdot / \cdot \pi r$} & $\left(1 / \Lambda \vee \Lambda, \Lambda / \Gamma_{0}\right)$ & $\cdot / \cdot r$ & $r / 110$ &.$/ 19 r$ & $0 / 1 \cdot 7$ & دارد & سابقه بسترى شدن \\
\hline & & \multicolumn{3}{|c|}{ رده مرجع } & & \multicolumn{2}{|l|}{ ن ل ندارد } \\
\hline & $(-7 / Y 7 /,-\cdot / r 77)$ & $\cdot / \cdot r \Lambda$ & $-Y / Y \mid \varepsilon$ &.$- / 1 r q$ & 政/ & دارد & مصرف دارو به غير \\
\hline & \multicolumn{5}{|c|}{ رده مرجع } & 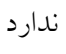 & از انسولين \\
\hline & $(-0 / \wedge \wedge \varepsilon, \cdot / \varepsilon \wedge 1)$ & .1 .97 & $-1 / 7 V T$ & $-\cdot / 1 \cdot \varepsilon$ & $-Y / V \cdot 1$ & دارد & سابقه خانوادگى \\
\hline & \multicolumn{5}{|c|}{ رده مرجع } & 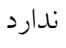 & ابتلا به ديابت \\
\hline
\end{tabular}

تنهايى در سالمندان مقيم خانواده در مقايسه با سالمندان

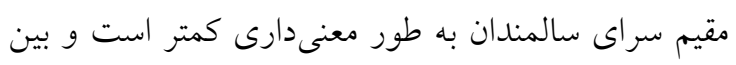

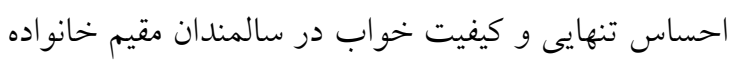

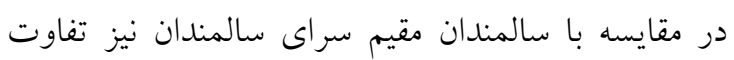

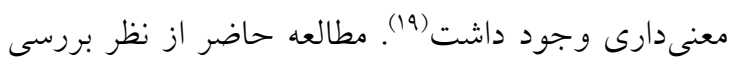

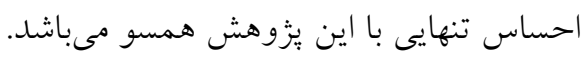

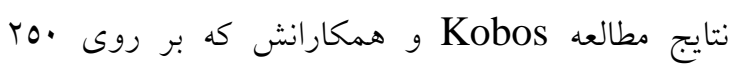

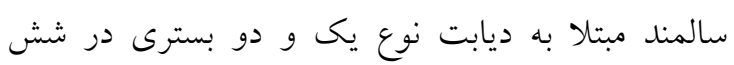

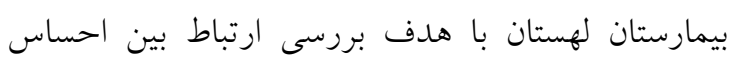
تنهايى و كنترل قند خون انجام شد، نشان داد كه تنها بـان 17

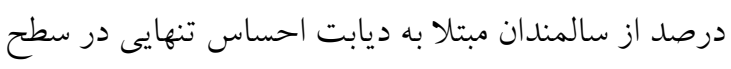
بالا داشتند و در بيشتر سالمندان مورد مطالعه همانند مطالعه

$$
\text { حاضر احساس تنهايى در سطح بايين بود (r.). }
$$

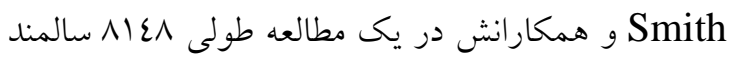

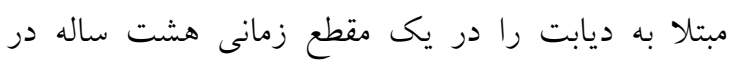

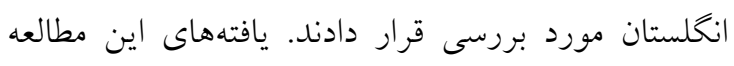

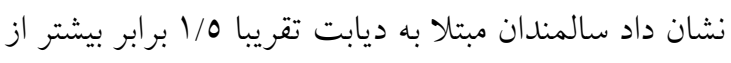
سالمندانى كه مبتلا به ديابت نيستند احساس تنهايى دارند.

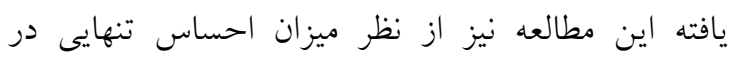
سالمندان مبتلا به ديابت با مطالعه حاضر مغايرت دارد.

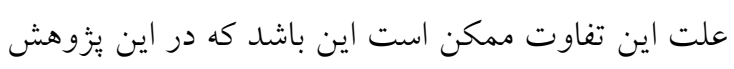

\section{بحث و نتيجهيرى}

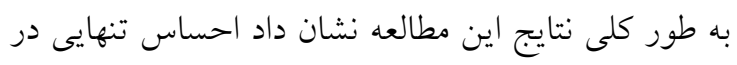
بين سالمندان شركت كننده در مطالعه در سطح بايين قرار

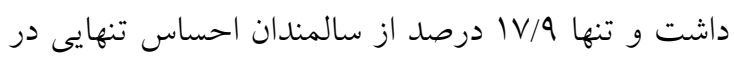
سطح بالا را كزارش كردند. همجِنين بررسى ارتباط احساس تنهايى با مشخصات جمعيت شناختى نشان داد

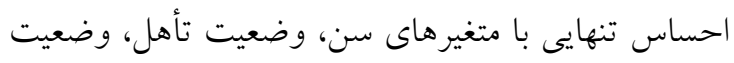

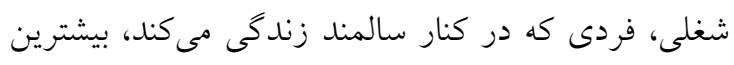

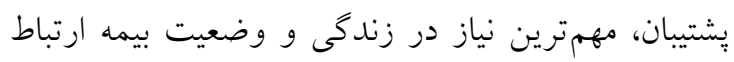

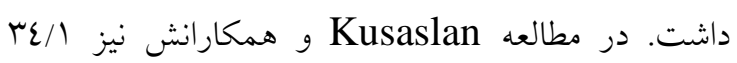
درصد افراد مبتلا به ديابت مراجعه كننده به يكى درمانغاه

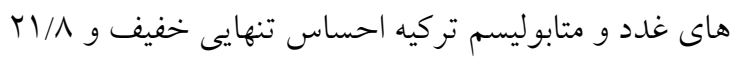

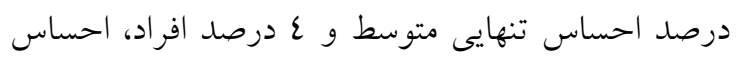

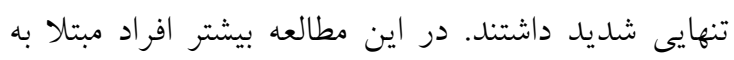
ديابت از احساس تنهايى متوسط تا شديد رنج مىبردند كه

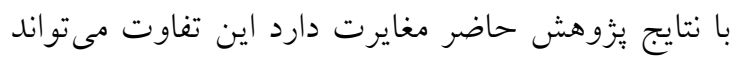

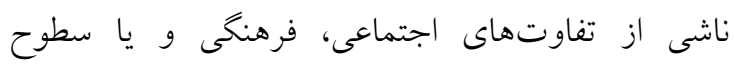
انتظارات و توقعات در بيماران مورد مطالعه باشد. در اين مطالعه نيز همانند مطالعه حاضر متغير احساس تنهايى به صورت معنىدارى با سطوح تحصيلات و وضعيت تأهل

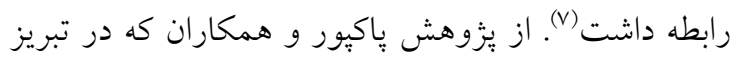

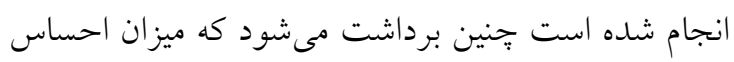


يافتهاى اين مطالعه نيز حاكى از ارتباط بين مشخصههاى

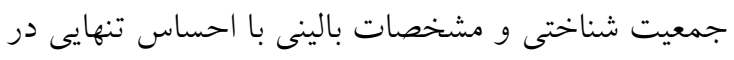

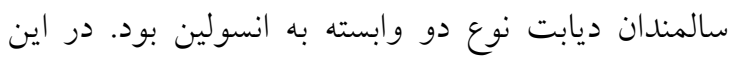

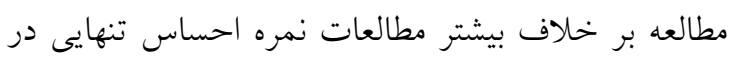
سطح بايين بود. اين مغايرت مىتواند به علت حضور

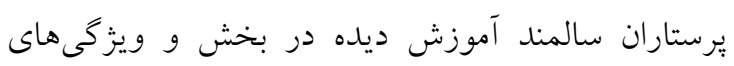

جمعيت شناختى و بالينى نمونهاى مورد مطالعه باشد. سر و صداى محيط و اختلال در تمركز سالمندان مورد

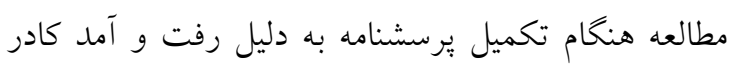

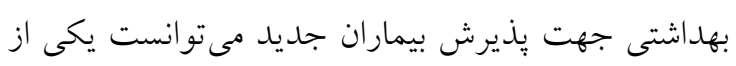

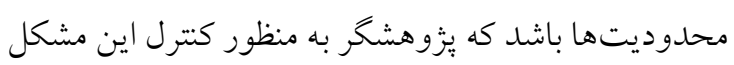

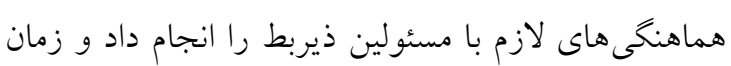

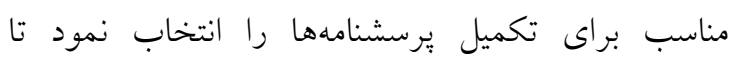

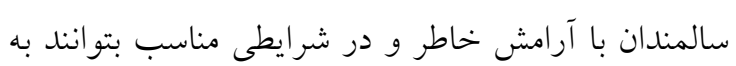
سؤ الات باسخ دهند. وضعيت جسمى و روحى فرد سالمند و زبان و كويشى كه دهن

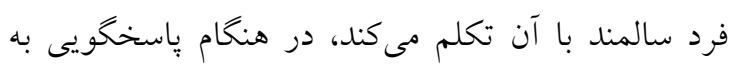

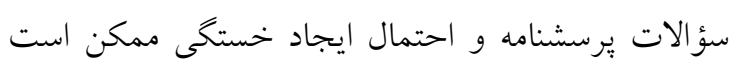

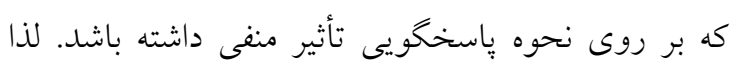

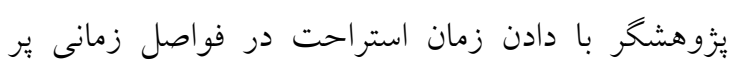

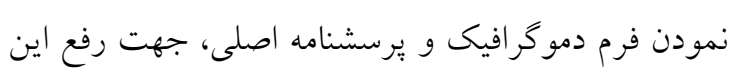

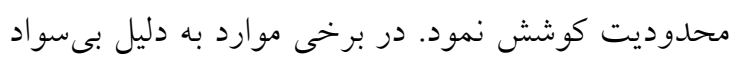

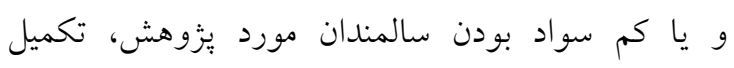

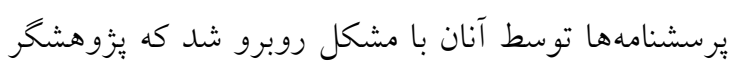

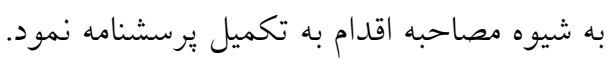

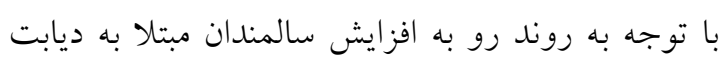

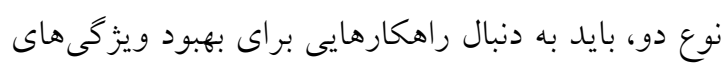

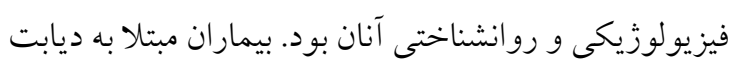

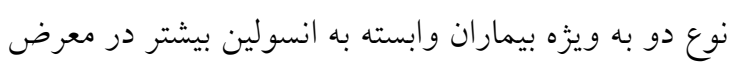

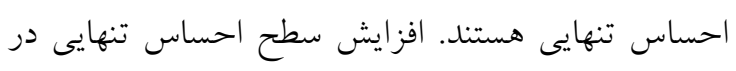

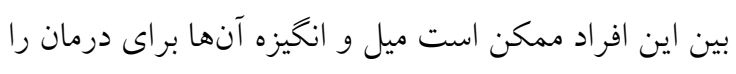

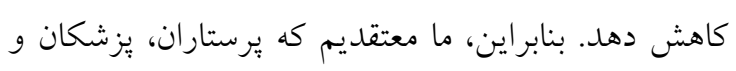

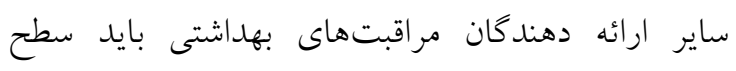
احساس تنهايى در جنين بيمارانى را در طول درمان و وانئ
تعداد افراد مورد مطالعه بيشتر بود و نمونهها در بازه زمانى

$$
\text { طولانى مدتى مورد بررسى قرار كرفتند (r). }
$$

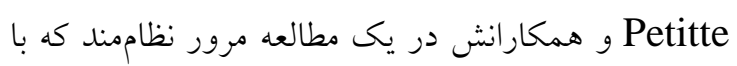
هدف تعيين ارتباط بين احساس تنهايى و بيمارىهاى مزمن فئن

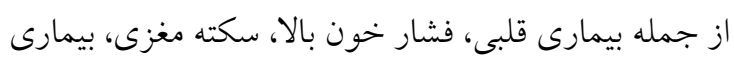

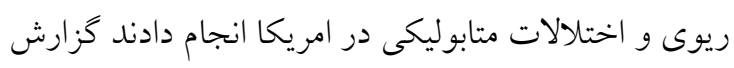

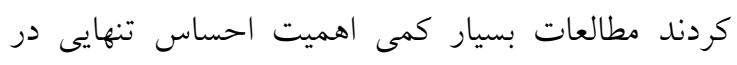

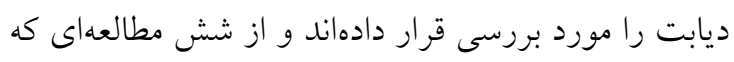

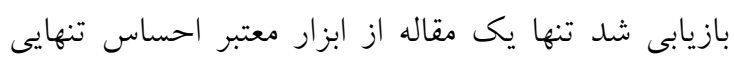

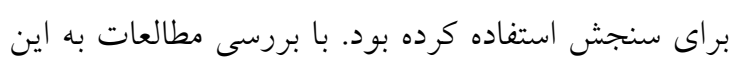

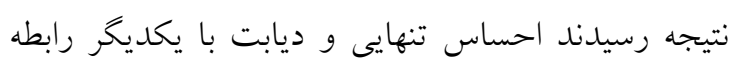

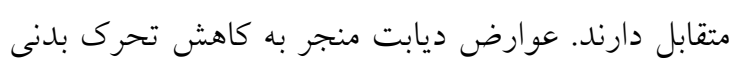

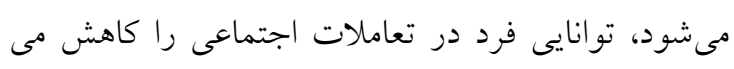

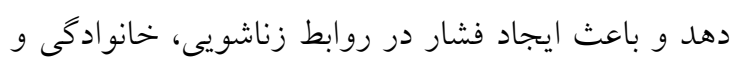

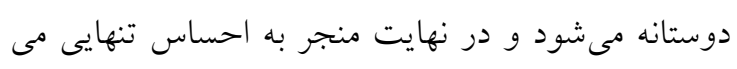

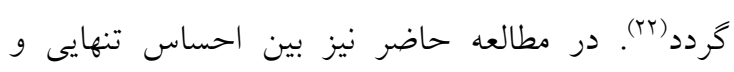
عوارض ناشى از ديابت (مشخصات بالينى سالمندان) ارتباط معنى دار وجود داشت.

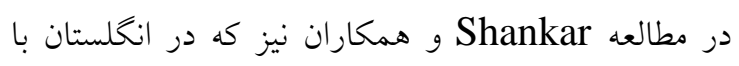

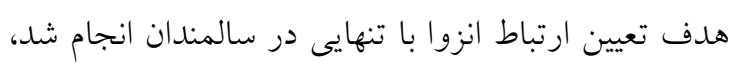

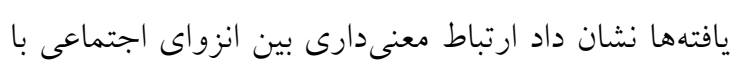
احساس تنهايى در جنبههاى مختلف وضعيت عملكردى وجود دارد. در اين مطالعه نيز همانند مطالعه حاضر دئه

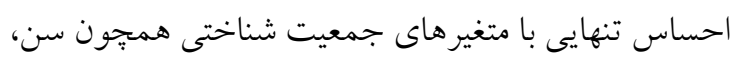
جنسيت، وضعيت سلامتى، رفاه، آموزش ارتباط معنى دار

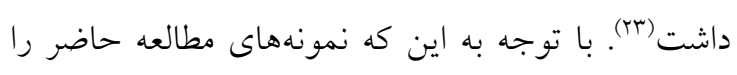

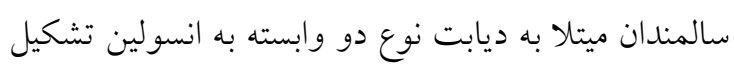

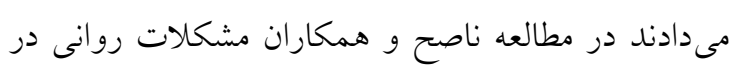

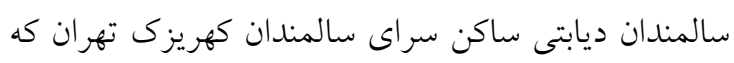
بيكار بودند به نسبت سالمندانى كه شغل داشتند بيشتر بود.

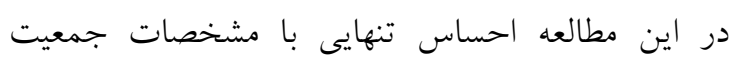
شناختى نظير شغل ارتباط معنى دار داشت (؟ع).

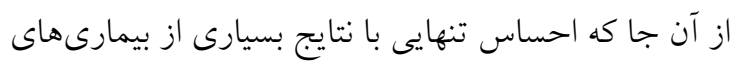

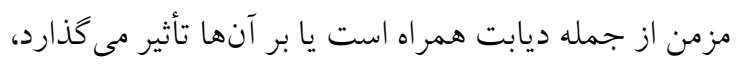




$$
\begin{aligned}
& \text { كلى جامعه نيستند، بهتر است جهت دستيابى به نتيجهاى } \\
& \text { مراقبتهاى بالينى همواره ارزيابى كنند. علاوه بر اين، } \\
& \text { كه كل جامعه را در برگيرد، اين مطالعه در وسعت بيشتر }
\end{aligned}
$$

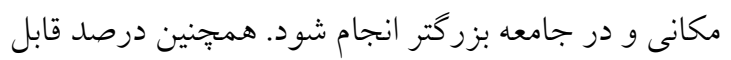

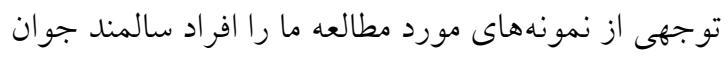

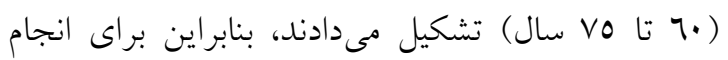

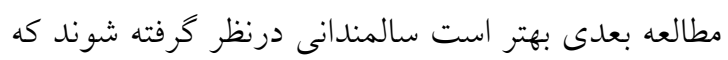

$$
\begin{aligned}
& \text { جزء سالمندان بير و يا خيلى بير باشند. }
\end{aligned}
$$

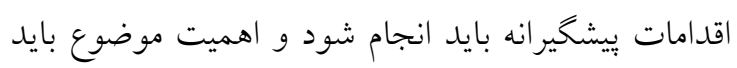

$$
\begin{aligned}
& \text { براى بيماران و اطرافيان آنها توضيح داده شود. }
\end{aligned}
$$

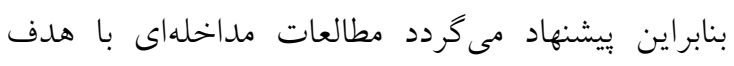

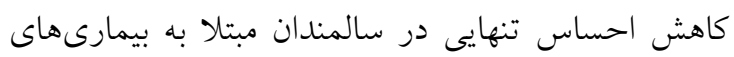

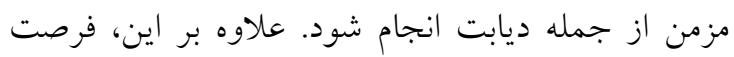

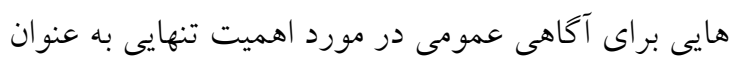

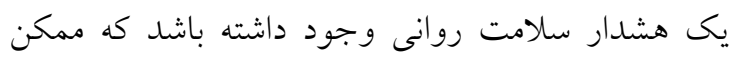

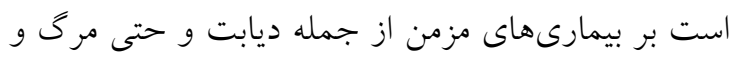

$$
\begin{aligned}
& \text { مير تأثير بخذارد. } \\
& \text { نويسندكان كزارش نشده است. } \\
& \text { سيستم مر اقبتهاى بهداشتى مىتواند با توسعه برنامههاى } \\
& \text { موفق جهت از بين بردن يا كاهش احساس تنهايى به طور }
\end{aligned}
$$

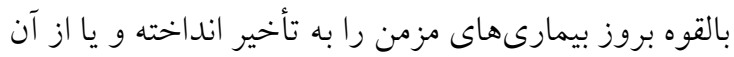

$$
\begin{aligned}
& \text { اين يُزوهش حاصل وِيايان نامه كارشناسى ارشد رشته }
\end{aligned}
$$

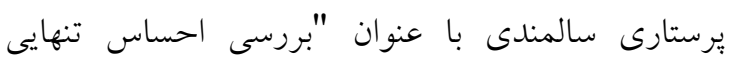

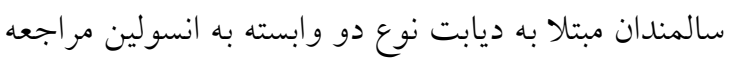

$$
\begin{aligned}
& \text { كننده به مراكز بهداشتى مراقبت جامع سالمندان دانشخاه } \\
& \text { علوم يزشكى ايران، سال يوسبا" مىباشد. }
\end{aligned}
$$

\section{References}

1. (IDF) IDF. Type 2 diabetes: IDF; 2020 [updated 20/03/2020; cited 2020 March 20]. Available from: https://idf.org/aboutdiabetes/type-2-diabetes.html.

2. Hosseinzadeh FY, Mohammadabadi MS, Aflakseir A. The Study of the Relationship between Social Support and Psychological Dimensions in Ms Patients. (JOURNAL OF HEALTH BREEZE) FAMILY HEALTH. 2015;4(2(14)):40-7. [Persian]

3. Wazaify M, Afifi FU, El-Khateeb M, Ajlouni K. Complementary and alternative medicine use among Jordanian patients with diabetes. Complemen Therap Clin Pract. 2011;17(2):71-5.

4. Egede LE, Dismuke CE. Serious psychological distress and diabetes: a review of the literature. Current psychiatry reports. 2012;14(1):15-22.

5. Patel YR, Gadiraju TV, Gaziano JM, Djoussé L. Adherence to healthy lifestyle factors and risk of death in men with diabetes mellitus: The Physicians' Health Study. Clinical Nutrition. 2018;37(1):139-43.

6. Kusaslan Avci D. Evaluation of the relationship between loneliness and medication adherence in patients with diabetes mellitus: a cross-sectional study. J Inter Med Res. 2018;46(8):3149-61.

7. Thaneerat T, Tangwongchai S, Worakul P. Prevalence of depression, hemoglobin A1C level, and associated factors in outpatients with type-2 diabetes. Asian Biomed. 2010;3(4):383-90.

8. Hazer O, Boylu AA. The examination of the factors affecting the feeling of loneliness of the elderly. ProcSocial Behav Sci. 2010;9:2083-9.

9. Arslantaş H, Adana F, Ergin FA, Kayar D, Acar G. Loneliness in elderly people, associated factors and its correlation with quality of life: A field study from Western Turkey. Iranian journal of public health. 2015;44(1):43. [Persian]

10. Foti SA, Khambaty T, Birnbaum-Weitzman O, Arguelles W, Penedo F, Giacinto RA, Gutierrez AP, Gallo LC, Giachello AL, Schneiderman N, Llabre MM. Loneliness, cardiovascular disease, 
and diabetes prevalence in the hispanic community health study/study of latinos sociocultural ancillary study. J Immig Minor Health. 2020;22(2):345-52.

11. Grover S, Verma M, Singh T, Dahiya N, Nehra R. Loneliness and its correlates amongst elderly attending non-communicable disease rural clinic attached to a tertiary care centre of North India. Asian J Psychiat. 2019;43:189-96.

12. Sarkadi A, Rosenqvist U. Field test of a group education program for type 2 diabetes: measures and predictors of success on individual and group levels. Patient education and counseling. 2001;44(2):129-39.

13. Rocca WA, Bonaiuto S, Lippi A, Luciani P, Pistarelli T, Grandinetti A, Cavarzeran F, Amaducci L. Validation of the Hodkinson abbreviated mental test as a screening instrument for dementia in an Italian population. Neuroepidemiology. 1992;11(4-6):288-95.

14. de Caso JG, Rodriguez-Artalejo F, Claveria LE, Coria F. Value of Hodkinson's test for detecting dementia and mild cognitive impairment in epidemiological surveys. Neuroepidemiology. 1994;13(1-2):64-8.

15. Bakhtiyari F, Foroughan M, Fakhrzadeh H, Nazari N, Najafi B, Alizadeh M, Arzaghi M, Sharifi F, Shoaee S, Mostafa Q. Validation of the persian version of Abbreviated Mental Test (AMT) in elderly residents of Kahrizak charity foundation. Iranian journal of Diabetes and Metabolism. 2014;13(6):487-94. [Persian]

16. Tsur N, Stein JY, Levin Y, Siegel A, Solomon Z. Loneliness and subjective physical health among war veterans: Long term reciprocal effects. Social Sci Medic. 2019;234:112373.

17. Rezaiee S, Farhadi H. Effectiveness of Quality of Life Therapy on Internet Addiction, Lonliness, and Selfe-steem of Female Second Grade High School Students. Knowl Res Appl Psychol. 2018;19(1):37-49. [Persian]

18. Pakpour V, Zamanzadeh V, Salimi S, Farsiv A, Moghbeli G, Soheili A. The relationship between loneness and sleep quality in older adults in Tabriz. Nursing And Midwifery Journal. 2017;14(11):906-17. [Persian]

19. Kobos E, Szewczyk A, Świątkowska T, Kryczka T, Sienkiewicz Z. Relationship between loneliness and blood glucose control in diabetes. BMC Public Health. 2020 Dec;20(1):1-6.

20. Smith K, Victor $C$. Investigating the longitudinal relationship between cardiometabolic conditions and loneliness in older people. Innovation in Aging. 2018;2(suppl_1):964.

21. Petitte T, Mallow J, Barnes E, Petrone A, Barr T, Theeke L. A systematic review of loneliness and common chronic physical conditions in adults. Open Osychol J. 2015;8(Suppl 2):113.

22. Shankar A, McMunn A, Demakakos P, Hamer M, Steptoe A. Social isolation and loneliness: Prospective associations with functional status in older adults. Health psychology. 2017;36(2):179.

23. Khodabakhshi-Koolaee A, Froozani A. Acomparison between loneliness and death anxiety among active and inactive elderly male living in nursing homes in Yazd. Nursing journal of the Vulnerable. 2018;5(16):1-15. [Persian]

24. Naseh H, Arzaghi M, ghasemzadeh R, rahimiforushani A, kamali M, Arastu A. Diabetic problematic domains in elderly diabetic resident in Kahrizak, Tehran. Iranian Journal of Diabetes and Lipid. 2012;11(5):449-54. [Persian] 